\title{
Eulerian Weather, Lagrangian Lives
}

\author{
Alan E. Stewart
}

$t$ is clear that COVID-19 is will be with us for a while. So will the weather, however. We have been through flooding in Michigan in mid-May; an outbreak of 140 tornadoes from Texas to Maryland in April; a deadly and destructive derecho in Iowa; hurricane landfalls in Louisiana, Alabama, and Florida; and massive wildfires in the West. In other words, the weather, as always, just is-it exists and occurs as a series of events that intertwine with the activities and challenges of our daily lives. Here, I would like to borrow from dynamic meteorology and apply the concepts of the Eulerian and Lagrangian perspectives to discuss our experiential journeys through the weather and COVID-19. I also will query what this means for how we cope when severe weather threatens us during this pandemic.

From the Eulerian perspective, we depict the current weather or make a forecast for a given space (county warning area, city, state, region) for a time (6 h, $12 \mathrm{~h}$, and so on). We concern ourselves with what will occur inside the grid boxes of a model-what is the flux of weather into and out of the area? Similarly, when we look out of the windows of our life spaces we see and experience the weather. And what is so striking about what we see is that most of the time the weather seems within its usual seasonal limitsclimatologically speaking. The weather is often pleasant. It seems not to have gotten the message about COVID-19.

How could it? The weather just is. Some people have told me that during the pandemic, the closures, and the quarantines, the weather is about the only thing that has remained normal in their lives-and this has provided some degree of comfort. But with a wildfire or a hurricane, this can change quickly. Some of the same states that are threatened by hurricane landfall already have been ravaged by COVID-19.

We can think of peoples' paths through the meteorological and nonmeteorological events in their lives with the Lagrangian perspective-metaphorically speaking. Life is a journey, a narrative, a path, or a force that moves forward in time; sometimes the trajectory changes unexpectedly. The Lagrangian perspective involves the accumulated experiences of the weather through the eyes of the perceivers-individual people. Such Lagrangian living with or "under" the weather builds a corpus of weather experiences that subtly or sometimes significantly changes peoples' subsequent responses to the weather (Stewart 2009). All of us are, to varying extents, products of what we have experienced, including the COVID-19 pandemic. So many people-in Michigan, Iowa, California, Louisiana, and elsewhere-have experienced life with both COVID-19 and disaster and displacement.

In dynamic meteorology we learn to use both the Eulerian and Lagrangian perspectives; we segue between the two to build a fuller understanding of the atmosphere. What might we learn and what questions arise when we juxtapose my uses of these perspectives? These are timely questions to consider as we deal with hurricanes, winter storms, and other weather threats during the COVID-19 pandemic.

\section{Trust of message sources}

During the COVID-19 pandemic, different state and federal agencies often have issued confusing, sometimes contradictory reports and recommendations about the virus (Goodnough and Sheikh 2020). How have peoples' experiences of this messaging affected the ways that they may receive and act upon forecasts, watches, and warnings for severe/extreme weather? How might weather-related messages from local emergency managers or health departments be received? To what extent has the trust in the weather enterprise been affected by pandemic-related messaging?

\section{Risk perception and tolerance}

People have dealt with multiple risks thus far during the pandemic: health, economic/financial, social, and psychological, among others (Blais and Weber 2006). Have the experiences of these risks affected how people perceive additional risks from thunderstorms, tornadoes, floods, and hurricanes? Because people may have successfully survived an infection with COVID-19, does this affect how they perceive their risks to natural hazards (Nakayachi

AFFILIATIONS: Stewart—University of Georgia, Athens, Georgia

CORRESPONDING AUTHOR: Alan E. Stewart, aeswx@uga.edu

DOI:10.1175/BAMS-D-20-0137.1

In final form 21 September 2020

C2021 American Meteorological Society

For information regarding reuse of this content and general copyright information, consult the AMS Copyright Policy. 
et al. 2015)? Do some people feel lucky? Because people may be more desperate for work or to keep a job, might they take additional risks to do their jobs during bad weather? Might some businesses take extra risks in bad weather to build a competitive advantage-to make up for past losses?

\section{Preparation}

As word of the pandemic spread, people in many places stocked up on consumables for daily living, leading to shortages of some items. Given how the pandemic has unfolded in different parts of the country, are people still prepared? Have they exhausted those supplies and are people fatigued from stocking up? Are suppliers ready for further waves of COVID-19 and/or a major hurricane landfall? Has stocking up and preparing made people more ready for severe weather? Is there a new appreciation for being prepared for the unexpected?

\section{Sheltering in place}

Some severe weather events involve sheltering in place. Given the extensive sheltering in many places in the spring because of COVID-19, would some prefer to shelter in place rather than risk COVID-19 exposure elsewhere? Alternatively, would some be less likely to shelter in place because they are fatigued from it?

\section{Evacuation planning}

Important questions involve what happens when evacuations are necessary. For example, how can the spread of COVID-19 infection be limited? Are separate shelters needed for those who are infected? How does social distancing work in the close quarters of a shelter? Are more shelters needed? Do the existing shelters have a supply of face masks and other personal protective equipment?

Interdisciplinary social and atmospheric science points to an ever-motivating realization. Often it is not simply a matter of providing a timely and accurate forecast, but it is what people do with the information they have that affects the outcomes (Sherman-Morris et al. 2018). This is unsettling because it is often out of the direct control of the weather enterprise-much as epidemiologists and physicians cannot control how people deal with the risks of COVID-19. Efforts to communicate effectively, educate, and persuade stakeholders about the weather take on great importance (Millet et al. 2020). Forecasts and warnings are absorbed by people who have experienced the varying and cumulative effects of COVID-19. Being mindful of this reality may help us to better prepare people and communities.

\section{FOR FURTHER READING}

Blais, A. R., and E. U. Weber, 2006: A domain-specific risk-taking (DOSPERT) scale for adult populations. Judgment Decis. Making, 1, 33-47, http://journal .sjdm.org/jdm06005.pdf.

Goodnough, A., and K. Sheikh, 2020: CDC weighs advising everyone to wear a mask. New York Times, 31 March, www.nytimes.com/2020/03/31/health /cdc-masks-coronavirus.html.

Millet, B., A. P. Carter, K. Broad, A. Cairo, S. D. Evans, and S. J. Majumdar, 2020: Hurricane risk communication: Visualization and behavioral science concepts. Wea. Climate Soc., 12, 193-211, https://doi .org/10.1175/WCAS-D-19-0011.1.

Nakayachi, K., H. M. Yokoyama, and S. Oki, 2015: Public anxiety after the 2011 Tohoku earthquake: Fluctuations in hazard perception after catastrophe. J. Risk Res., 18, 156-169, https://doi.org/10.1080/1366 9877.2013.875936.

National Academies of Sciences, Engineering and Medicine, 2020: Rapid expert consultation on SARS-CoV-2 survival in relation to temperature and humidity and potential for seasonality for the COVID-19 pandemic (April 7, 2020). National Academies of Sciences, Engineering and Medicine Rep., 7 pp., https://doi .org/10.17226/25771.

Sherman-Morris, K., H. Lussenden, A. Kent, and C. MacDonald, 2018: Perceptions about social science among NWS warning coordination meteorologists. Wea. Climate Soc., 10, 597-612, https://doi .org/10.1175/WCAS-D-17-0079.1.

Stewart, A. E., 2009: Minding the weather: The measurement of weather salience. Bull. Amer. Meteor. Soc., 90, 1833-1842, https://doi .org/10.1175/2009BAMS2794.1. 